\title{
The impact of readiness to discharge from hospital on adherence to treatment in patients after myocardial infarction
}

Agata Kosobucka ${ }^{1 *}$, Piotr Michalski ${ }^{1 *}$, Łukasz Pietrzykowski ${ }^{1}$, Michał Kasprzak ${ }^{2}$, Tomasz Fabiszak ${ }^{2}$, Mirosława Felsmann ${ }^{3}$, Aldona Kubica ${ }^{1}$

${ }^{1}$ Department of Health Promotion, Collegium Medicum,

Nicolaus Copernicus University, Bydgoszcz, Poland

${ }^{2}$ Department of Cardiology and Internal Diseases, Collegium Medicum,

Nicolaus Copernicus University, Bydgoszcz, Poland

${ }^{3}$ Laboratory of Basic Clinical Skills and Medical Simulations,

Collegium Medicum, Nicolaus Copernicus University, Bydgoszcz, Poland

\begin{abstract}
Background: The healthcare professionals involved in in-hospital treatment of myocardial infarction (MI) are also responsible to patients for their education before leaving the hospital. This education aims to modify patient behaviour in order to reduce relevant risk factors and improve self-control and adherence to medications. The aim of the study was to analyse the relationship between readiness for discharge from hospital and adherence to treatment at follow-up in MI patients.

Methods: An observational, single-center, MI cohort study with 6-month follow-up was conducted between May 2015 and July 2016. The Readiness for Hospital Discharge after Myocardial Infarction Scale (RHD-MIS) and the Adherence in Chronic Diseases Scale (ACDS) were applied.

Results: Two hundred and thirteen patients aged 30-91 years (62.91 \pm 11.26$)$ were enrolled in the study. The RHD-MIS general score ranged from 29 to 69 points (51.16 \pm 9.87$)$. A high level of readiness was found in 66 (31\%) patients, intermediate in 92 (43.2\%), and low in 55 (25.8\%) of patients. Adherence level assessed with the ACDS 6-months after discharge from hospital ranged from 7 to 28 points (23.34 \pm 4.06$)$. An increase in objective assessment of patient knowledge according to RHD-MIS subscale resulted in significantly higher level of adherence at the follow-up visit $(p=0.0154) ; R$ Spearman $=0.16671, p=0.015 ;$ f for trend $=0.005$. During the 6 -month follow-up $3(1.41 \%)$ patients died and $17(7.98 \%)$ were hospitalized for a subsequent acute coronary syndrome.

Conclusions: This study provided preliminary evidence of a long-term association between the results of assessment of readiness for discharge from hospital and adherence to treatment in patients after MI. (Cardiol J 2022; 29, 4: 582-590)

Key words: readiness for discharge from the hospital, adherence, myocardial infarction, coronary artery disease, antiplatelet treatment, questionnaire, scale
\end{abstract}

\section{Introduction}

Adherence to medications after discharge from hospital is required for effective treatment of chronic diseases, including ischemic heart disease [1]. It is estimated that up to $60-80 \%$ of patients do not follow recommendations during long-term therapy [1-3], making it impossible to achieve therapy goals. In order to achieve patient's active involvement in the therapeutic process, it is necessary to provide the patient with some elementary knowledge about the disease and its treatment.

Address for correspondence: Agata Kosobucka, M.N.Sc, Department of Health Promotion, Nicolaus Copernicus University, Collegium Medicum, ul. Lukasiewicza 1, 85-821 Bydgoszcz, Poland, tel: +48 662-664-800, e-mail: akosobucka@wp.pl

Received: 9.10.2019 Accepted: 1.01.2020 Early publication date: 5.02 .2020

*Both authors equally contributed and should be recognized as first authors.

This article is available in open access under Creative Common Attribution-Non-Commercial-No Derivatives 4.0 International (CC BY-NC-ND 4.0) license, allowing to download articles and share them with others as long as they credit the authors and the publisher, but without permission to change them in any way or use them commercially. 
Therefore, effective health education is essential for successful therapy $[4,5]$. The healthcare professionals involved with in-hospital treatment of patients with myocardial infarction (MI) are also responsible for their preparation for discharge from hospital including education aimed to modify the risk factor profile, improve self-control and adherence to treatment [6-10]. In order to evaluate the effectiveness of preparation for the discharge procedure, the Readiness for Hospital Discharge after Myocardial Infarction Scale (RHD-MIS) was developed [11]. It is not clear, however, to what extent the level of readiness to discharge in patients after MI affects their subsequent adherence to therapeutic recommendations.

Presented data were collected as a part of a wider master project titled 'The influence of education on adherence'. Some results of the project have already been published $[12,13]$.

The aim of this study was to evaluate the long-term relationship between readiness for discharge from hospital and adherence to treatment in MI patients.

\section{Methods}

An observational, single-center, cohort study with 6-month follow-up was conducted at the Jurasz University Hospital in Bydgoszcz, Poland. The master project titled 'The influence of education on adherence' was approved by The Bioethics Committee of the Collegium Medicum, Nicolaus Copernicus University in Torun (No. KB $312 / 2015$ of $21 / 04 / 2015$ ). The research was performed in accordance with the Declaration of Helsinki and International Conference on Harmonization/Good Clinical Practice and applicable regulatory requirements. Consecutive patients treated with percutaneous coronary intervention (PCI) due to MI between May 2015 and July 2016 were considered eligible for the study. Subjects with cognitive or physical impairment, prisoners, soldiers, and patients remaining in any personal relationship with researchers were excluded. A written informed consent was acquired from all study participants before enrollment [12]. All patients during hospitalization and follow-up were treated according to current guidelines of the European Society of Cardiology [10]. Patients enrolled in the study received in-hospital education as a part of an in-hospital rehabilitation program, and were then seen in the out-patient clinic every 2 months up to 6 months after hospital discharge. Patients who missed their follow-up visit were contacted by phone and telephone follow-up was performed. The information regarding re-hospitalization or death of study participants was retrieved from the National Health Fund [12].

An in-hospital standardized educational program, which was a pivotal element of the procedure in patient preparation for discharge, was conducted by educational nurses in cooperation with physiotherapists, dietitians and physicians in all patients. The program includes information regarding pathophysiology of coronary artery disease, symptoms and treatment of the disease, diet, physical activity, and plan for outpatient control visits. Readiness for discharge from hospital was assessed with the RHD-MIS [11]. Adherence to treatment at followup was evaluated with The Adherence in Chronic Diseases Scale (ACDS) [14, 15]. Both scales were developed and validated in patients after MI [11, 15] and are available free of charge on the website of the Department of Health Promotion, Collegium Medicum, Nicolaus Copernicus University, Poland (https://www.cm.umk.pl/wydzialy/wydzial-nauk-ozdrowiu/jednostki-wydzialowe/katedra-i-zakladpromocji-zdrowia.html).

The RHD-MIS consists of three subscales: (1) subjective, and (2) objective assessment of patient knowledge about the disease, and (3) patient expectations [11]. A score from 0 to 3 was assigned for each of 23 RHD-MIS items. The questionnaire also contains non-scored questions regarding patients' opinions related to disease, treatment and prevention. A total RHD-MIS score of more than 57 points indicates high readiness for discharge, less than 44 points - low readiness, while medium readiness was defined as scores between 44 and 57 points. The previously reported an alpha-Cronbach coefficient of 0.789 indicates high reliability and homogeneity of this questionnaire. Moreover, internal consistency analysis of the RHD-MIS, three areas confirmed the appropriateness of the subscale distinction $[11,12]$.

Adherence to medication was assessed with standardized, self-reported questionnaire - the ACDS. The scale includes 7 questions with sets of 5 suggested answers to each question. Depending on the answer, each item of the scale is awarded 0-4 points. A score of more than 26 points reflects high adherence to treatment, while scores of 21-26, and less than 21 points respectively, correspond to intermediate and low adherence. According to the validation study, the ACDS questionnaire has a satisfactory level of reliability and homogeneity (alpha-Cronbach coefficient of 0.752) [13]. The ACDS is designed for surveying 
adults treated for chronic diseases and reflects the actual implementation of a treatment plan regarding pharmacotherapy.

The first section of RHD-MIS, as well as the entire ACDS were completed by patients under the supervision of a data collecting nurse.

All enrolled patients were evaluated with the RHD-MIS on the day of discharge from hospital, while the ACDS was assessed 6-months after discharge [12]. Concordance between the subjective and objective assessment of knowledge with the RHD-MIS was recognized when the results of both subscales were in the same score ranges (high and high, intermediate and intermediate, or low and low); extremely different scores (high and low) of subjective and objective assessment of knowledge were defined as extreme discordance; any other combination of subscale results was classified as discordant.

In order to ensure accuracy and completeness of data collection, special care was taken to assure study participants of anonymity and confidentiality of the information obtained from both questionnaires. The data collecting staff also did their best to avoid influencing patient responses [12]. All data collection, including supervision of questionnaire completion, was performed by three co-authors of this paper (AKo, $\mathrm{PM}$ and $€ \mathrm{P}$ ).

\section{Statistical analysis}

Statistical analysis was performed using Statistica 12.0 software (StatSoft, Tulsa, USA). Medians with interquartile ranges and means with standard deviations were used for continuous variables presentation. Normality of data distribution was verified with the Shapiro-Wilk test. Due to a lack of normal distribution of the investigated continuous variables, non-parametric tests were used for statistical analysis. The Mann-Whitney unpaired rank sum test was applied for comparisons between the two groups. Comparisons between three or more groups were performed with the Kruskal-Wallis one-way analysis of variance for assessment of heterogeneity. For evaluation of trends the Jonckheere-Terpstra test was used. The degree of association between two variables was assessed with the Spearman rank correlation test. The results were considered significant at $\mathrm{p}<0.05[12]$.

\section{Results}

\section{General results}

The study population consisted of 213 patients (59 women and 154 men) aged from 30 to 91 years

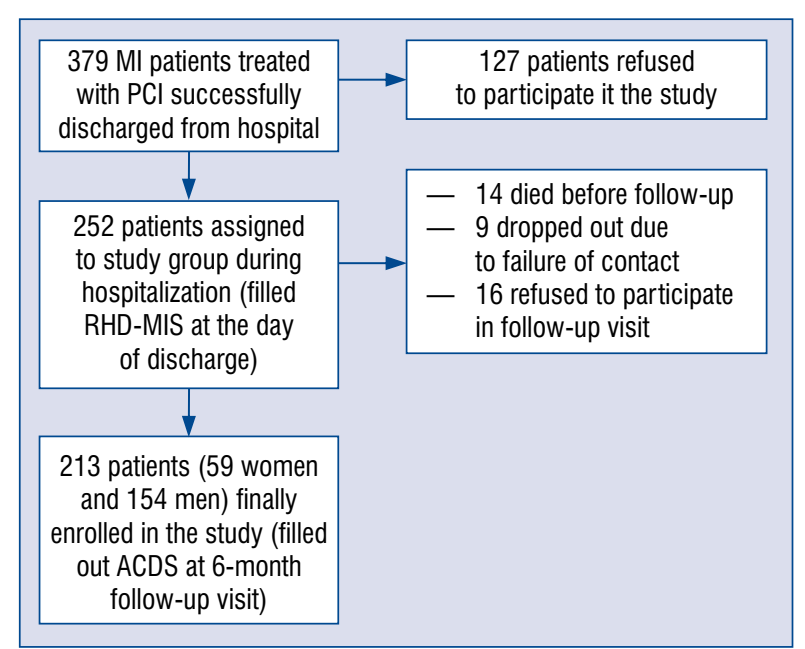

Figure 1. A study flow chart; $\mathrm{Ml}$ - myocardial infarction; $\mathrm{PCl}$ - percutaneous coronary intervention; ACDS - Adherence in Chronic Diseases Scale; RHD-MIS - Readiness for Hospital Discharge after Myocardial Infarction Scale.

(average $62.91 \pm 11.26$ years), with complete data collected at baseline hospitalization and at followup visit (Fig. 1) [12].

Out of 379 consecutive patients who met the inclusion criteria during hospitalization and were successfully discharged from hospital, 166 individuals were not enrolled in the study (127 of them did not provide their consent for participation in the study, 14 died after discharge from hospital, but before the follow-up visit, 9 were lost to follow-up due to failure of contact, and 16 refused to participate in follow-up or provided incomplete answers precluding data analysis) [12]. Only 37 (17.4\%) patients participated in a rehabilitation program after discharge. The characteristics of the study population is shown in Table 1 [12].

The level of readiness for discharge from hospital was assessed with the RHD-MIS general score which ranged from 29 to 69 points with a median of 52 and an average score of $51.16 \pm 9.87$. A high level of readiness was found in $66(31 \%)$ patients, intermediate in $92(43.2 \%)$, and low in $55(25.8 \%)$ of patients. The results obtained with each of the three subscales are shown in Table 2.

According to multiple comparison tests, none of the analyzed sociodemographic nor clinical factors were associated with the RHD-MIS general score. Regarding the RHD-MIS subscales, knowledge about coronary artery disease according to an objective assessment was associated with gender (higher for female; $p=0.012$ ) and with place of 
Table 1. Study population characteristics.

\begin{tabular}{|c|c|c|}
\hline Parameter & Variable & $\begin{array}{l}\text { Total sample } \\
(n=213)\end{array}$ \\
\hline \multirow[t]{2}{*}{ Gender } & Female & $59(27.7 \%)$ \\
\hline & Male & $154(72.3 \%)$ \\
\hline \multirow[t]{2}{*}{ Age } & $<65$ & 119 (55.87\%) \\
\hline & $\geq 65$ & $94(43.13 \%)$ \\
\hline \multirow[t]{4}{*}{ Education } & Primary & $26(12.21 \%)$ \\
\hline & Vocational & $77(36.15 \%)$ \\
\hline & Secondary & $79(37.09 \%)$ \\
\hline & Higher & $31(14.55 \%)$ \\
\hline \multirow[t]{4}{*}{ Employment status } & Employed & $86(40.38 \%)$ \\
\hline & Unemployed & $13(6.1 \%)$ \\
\hline & OA pensioner & $86(40.38 \%)$ \\
\hline & DLA recipient & $28(13.1 \%)$ \\
\hline \multirow[t]{4}{*}{ Economic status } & Very good & $12(5.63 \%)$ \\
\hline & Acceptable & $190(89.2 \%)$ \\
\hline & Bad & $11(5.16 \%)$ \\
\hline & Very bad & $0(0.0 \%)$ \\
\hline \multirow[t]{3}{*}{ Place of residence* } & City & $112(52.58 \%)$ \\
\hline & Town & $45(21.13 \%)$ \\
\hline & Village & $56(26.29 \%)$ \\
\hline \multirow[t]{3}{*}{ Marital status } & Unmarried & $21(9.86 \%)$ \\
\hline & Married & $163(76.53 \%)$ \\
\hline & Widowed & $29(13.62 \%)$ \\
\hline \multirow[t]{2}{*}{ Living status } & Alone & $25(11.74 \%)$ \\
\hline & With family & $188(88.26 \%)$ \\
\hline \multirow{2}{*}{$\begin{array}{l}\text { Prior hospitalization } \\
\text { for CAD }\end{array}$} & Yes & $131(61.50 \%)$ \\
\hline & No & $82(38.5 \%)$ \\
\hline \multirow[t]{2}{*}{ History of CAD } & Yes & $100(46.95 \%)$ \\
\hline & No & $113(53.05 \%)$ \\
\hline \multirow[t]{2}{*}{ Prior MI } & Yes & $60(28.17 \%)$ \\
\hline & No & $153(71.83 \%)$ \\
\hline \multirow[t]{2}{*}{ Prior $\mathrm{PCl}$} & Yes & $80(37.56 \%)$ \\
\hline & No & $133(62.44 \%)$ \\
\hline \multirow[t]{2}{*}{ Prior CABG } & Yes & $32(15.02 \%)$ \\
\hline & No & $181(84.98 \%)$ \\
\hline \multirow[t]{2}{*}{ Hypertension } & Yes & $157(73.71 \%)$ \\
\hline & No & $56(26.29 \%)$ \\
\hline \multirow[t]{2}{*}{ Hyperlipidemia } & Yes & 145 (68.08\%) \\
\hline & No & $68(31.92 \%)$ \\
\hline \multirow[t]{3}{*}{ Smoking status } & Yes (current) & $74(34.74 \%)$ \\
\hline & No (current) & 139 (65.26\%) \\
\hline & Ex-smoker & $51(23.94 \%)$ \\
\hline \multirow[t]{2}{*}{ Family burden } & Yes & $128(60.09 \%)$ \\
\hline & No & $85(39.91 \%)$ \\
\hline \multirow[t]{2}{*}{ Diabetes } & Yes & $61(28.64 \%)$ \\
\hline & No & $152(71.36 \%)$ \\
\hline
\end{tabular}

${ }^{*}$ City > 100,000 inhabitants; Town $\leq 100,000$ inhabitants; OA - old age; DLA — disability living allowance; CAD — coronary artery disease; $\mathrm{MI}$ - myocardial infarction; $\mathrm{PCl}$ - percutaneous coronary intervention; CABG - coronary artery bypass grafting residence (higher for city dwellers; $\mathrm{p}=0.025$ ). Economic status was found to have an impact on patient expectations (higher for lower status; $\mathrm{p}=$ $=0.014)$; no association between the factors analyzed and subjective assessment of knowledge was found. Detailed results concerning those factors have been previously published [12].

The results of ACDS were influenced by age (higher for patients $<65$ years of age; $p=0.0005$ ) and previous $\mathrm{MI}$ (lower for patients with MI before the index event; $\mathrm{p}=0.005$ ).

A comparison of subjective and objective assessment of patient knowledge revealed concordance in $90(42.3 \%)$ subjects, while discordance was observed in 123 (57.7\%) patients. Moreover, an extreme mismatch (low and high level) occurred in $24(11.3 \%)$ patients (Table 3$)$.

The adherence to prescribed medication assessment with the ACDS at 6 months after discharge from the hospital resulted in a score from 7 to 28 (median of 24 points; average of $23.34 \pm$ $\pm 4.06)$. A score of over 26 points classified as high was obtained by 56 (26.3\%) patients, an intermediate score (between 21 and 26 points) was found in $106(49.8 \%)$ subjects and in $51(23.9 \%)$ patients the score was under 21 points was defined as low.

\section{Detailed results}

A comparison of RHD-MIS general score according to ACDS scores in all patients enrolled in the study did not reveal any significant differences, only a trend $(\mathrm{p}=0.038)$ suggesting higher adherence at follow-up in patients with a higher level of readiness for discharge was found (Table 2). However, in subjects showing concordance between subjective and objective assessment of patient knowledge, higher ACDS results were associated with higher RHD-MIS general scores (ACDS score of $22.64 \pm 4.83,23.34 \pm 2.94$, and $24.97 \pm 3.55$ for low, intermediate and high RHD-MIS general score, respectively, $\mathrm{p}=0.018$ ). The comparison of these ACDS scores showed differences for low vs. high $(\mathrm{p}=0.023)$ and intermediate vs. high $(\mathrm{p}=0.014)$, but not for low vs. intermediate $(\mathrm{p}=0.099)$ RHD-MIS general score.

Among the RHD-MIS subscales, the increase in objective assessment of patients resulted in significantly higher level of adherence at follow-up visit $(\mathrm{p}=0.0154)$; $\mathrm{R}$ Speraman $=0.16671$, $\mathrm{p}=0.015 ; \mathrm{p}$ for trend $=0.005$. The results of the remaining RHD-MIS subscales did not show a relationship with ACDS results. Nevertheless, the high result of RHD-MIS general score as well as high results of all subscales of RHD-MIS were 
Table 2. Readiness for Hospital Discharge after Myocardial Infarction Scale (RHD-MIS) scores with regard to Adherence in Chronic Diseases Scale (ACDS) score level.

\begin{tabular}{lcccc}
\hline ACDS & $\begin{array}{c}\text { RHD-MIS } \\
\text { General score }\end{array}$ & \multicolumn{3}{c}{ RHD-MIS subscales scores } \\
\cline { 3 - 5 } & & $\begin{array}{c}\text { Subjective } \\
\text { knowledge }\end{array}$ & $\begin{array}{c}\text { Objective } \\
\text { knowledge }\end{array}$ & $\begin{array}{c}\text { Patient } \\
\text { expectations }\end{array}$ \\
\hline Low score $(\mathrm{n}=51)$ & $49.06 \pm 10.45$ & $17.24 \pm 3.35$ & $15.47 \pm 3.59$ & $16.35 \pm 7.34$ \\
Intermediate score $(\mathrm{n}=106)$ & $51.29 \pm 9.57$ & $17.75 \pm 3.17$ & $15.49 \pm 3.42$ & $18.05 \pm 6.67$ \\
High score $(\mathrm{n}=56)$ & $52.84 \pm 9.70$ & $18.34 \pm 3.18$ & $16.73 \pm 3.17$ & $17.77 \pm 7.25$ \\
\hline
\end{tabular}

Table 3. Readiness for Hospital Discharge after Myocardial Infarction Scale (RHD-MIS) regarding patient knowledge - concordance of subjective and objective assessment.

\begin{tabular}{lccc}
\hline Level of knowledge & Objective low & Objective intermediate & Objective high \\
\hline Subjective low & $22(10.3 \%)$ & $22(10.3 \%)$ & $8(3.8 \%)$ \\
Subjective intermediate & $15(7.0 \%)$ & $32(15.0 \%)$ & $11(5.2 \%)$ \\
Subjective high & $16(7.5 \%)$ & $51(23.9 \%)$ & $36(16.9 \%)$ \\
\hline
\end{tabular}

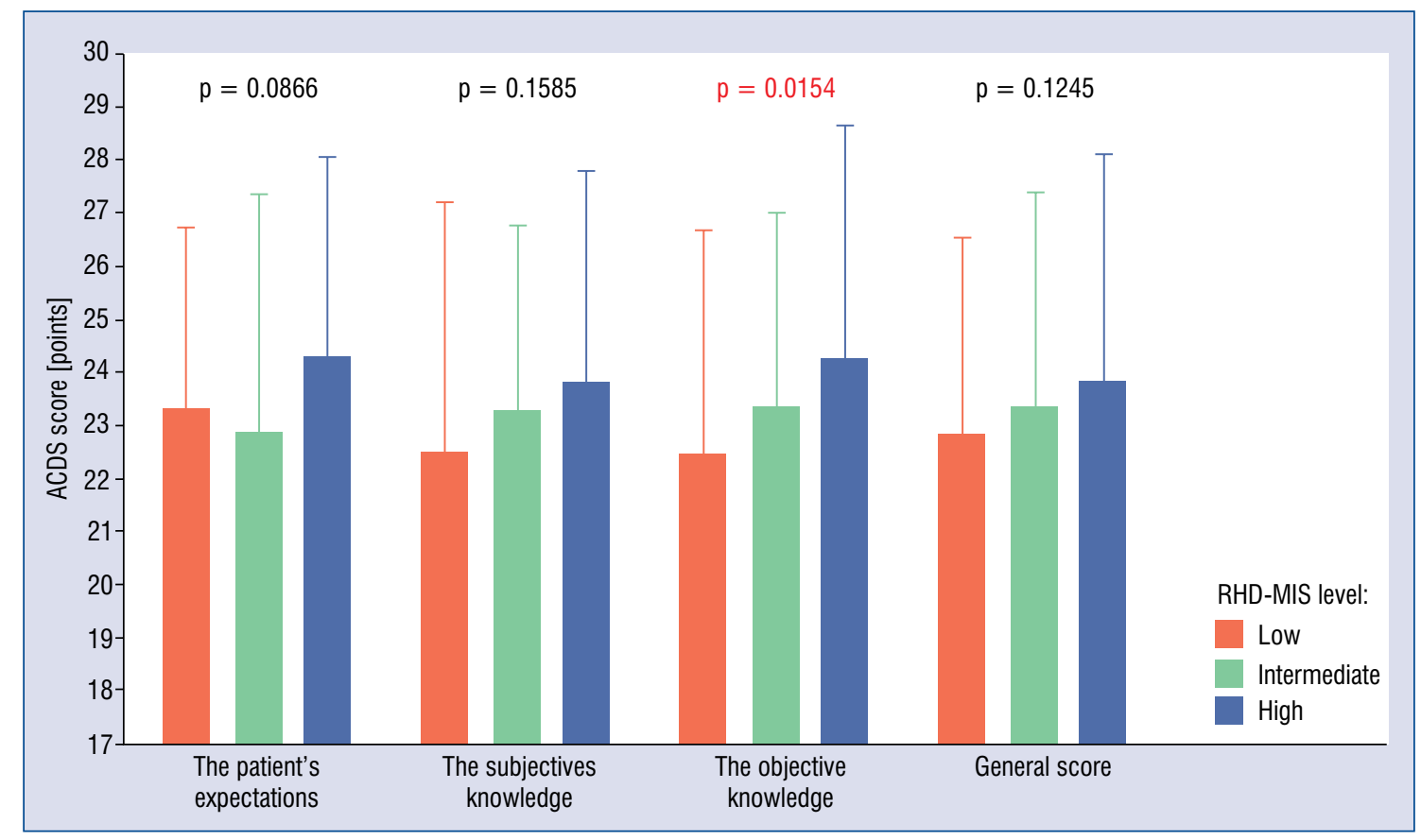

Figure 2. Comparison of Adherence in Chronic Diseases Scale (ACDS) scores with regard to Readiness for Hospital Discharge after Myocardial Infarction Scale (RHD-MIS) results (general score and subscale scores).

associated with the highest adherence level according to ACDS (Fig. 2).

RHD-MIS and ACDS scores were analysed according to patient opinions expressed in nonscored RHD-MIS items (Figs. 3, 4). Due to the distribution of answers, answers "Yes" and "I guess so" were combined and compared vs. answers "I do not" and "I'm not sure". The statistical analysis of RHD-MIS was not performed for the first opinion (A), as almost all patients (210 vs. 3 ) answered "Yes" or "I guess so". For all remaining opinions significant differences regarding RHD-MIS were 


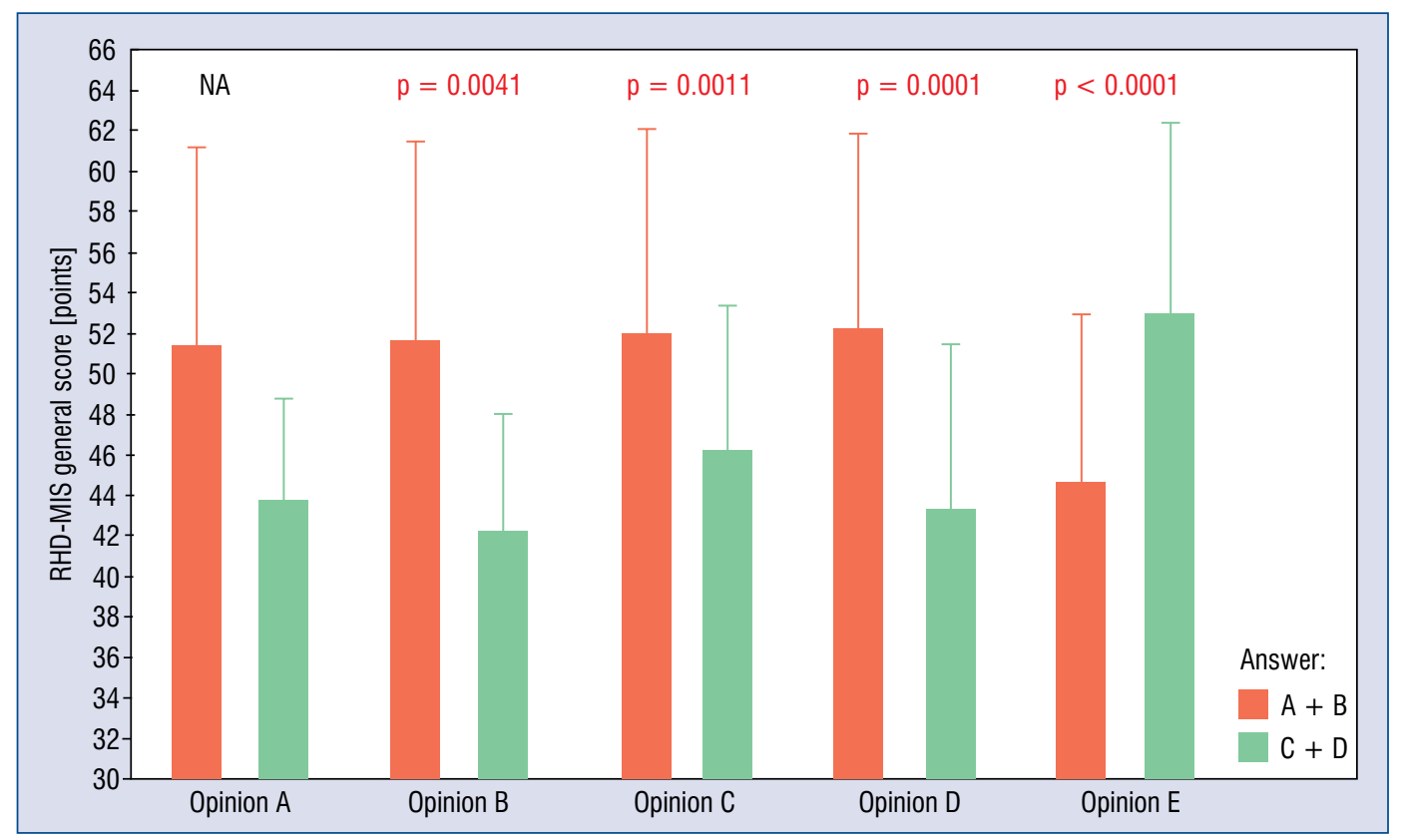

Figure 3. Readiness for Hospital Discharge after Myocardial Infarction Scale (RHD-MIS) general score with regard to patients' opinions; NA - not applicable

Opinion A. Do you think that the illness being the reason for your hospitalisation is serious?

Opinion B. Do you think that despite the medication, you need to change your lifestyle to prevent illness recurrence? Opinion C. Do you think that systematic medication reduces the risk of reinfarction?

Opinion D. Can you rely on the help of family or other people to comply with your doctor's recommendations?

Opinion E. Do you think your return home is associated with additional hazards?

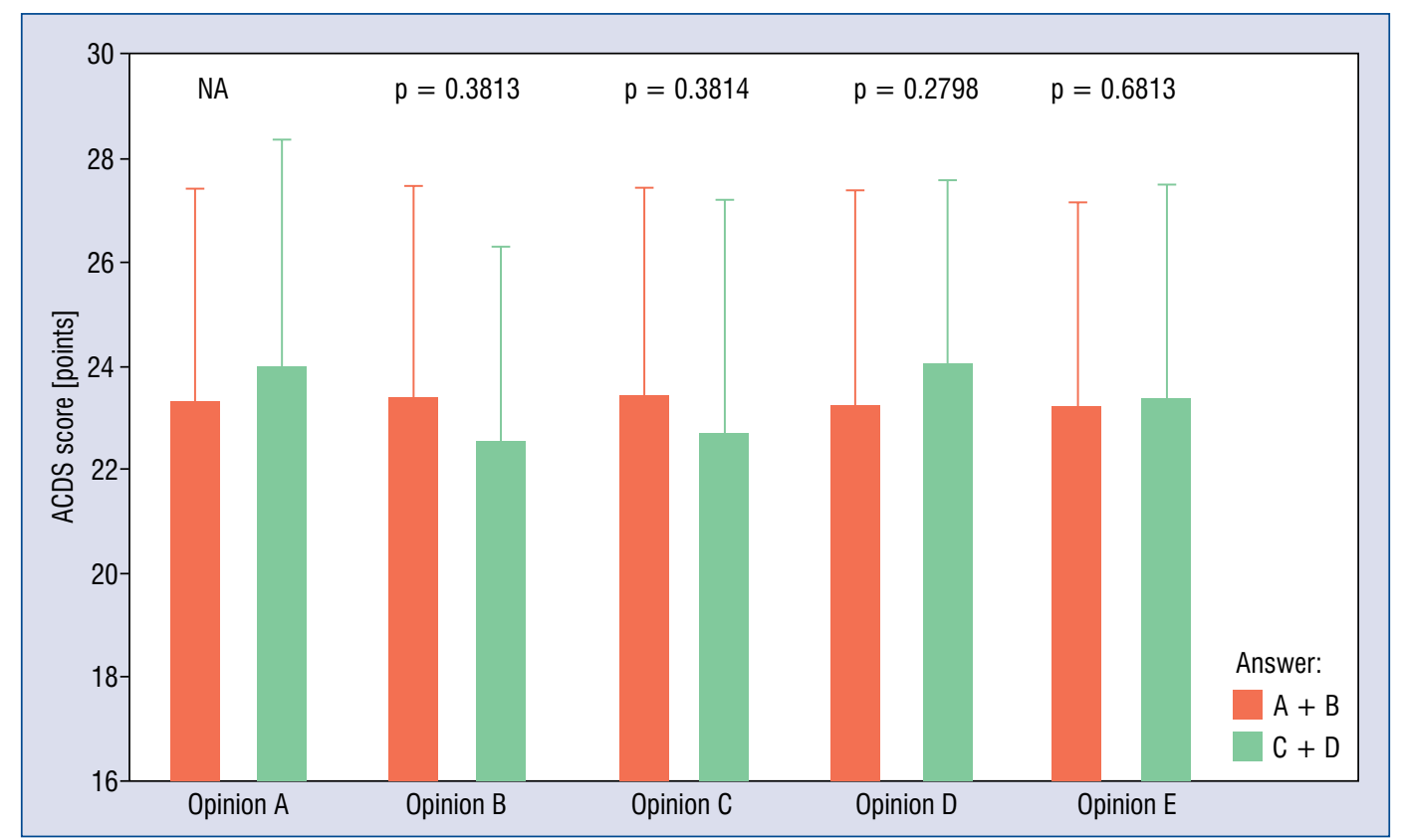

Figure 4. Adherence in Chronic Diseases Scale (ACDS) score with regard to patients' opinions; NA — not applicable Opinion A. Do you think that the illness being the reason for your hospitalisation is serious?

Opinion B. Do you think that despite the medication, you need to change your lifestyle to prevent illness recurrence? Opinion C. Do you think that systematic medication reduces the risk of reinfarction?

Opinion D. Can you rely on the help of family or other people to comply with your doctor's recommendations?

Opinion E. Do you think your return home is associated with additional hazards? 
found (Fig. 2); for B, C, and D the mean score was higher with answers "Yes" and "I guess so", while for opinion $\mathrm{E}$ it was higher with answers "I do not" and "I'm not sure" (Fig. 3). The ACDS scores did not differ with regard to patient opinions (Fig. 4).

Moreover, significant differences in scores of RHD-MIS sub-scale 1 (subjective assessment of patient knowledge about the disease) were observed between patients answering "Yes" and "I guess so" vs. "I do not" and "I'm not sure" for the following opinions: B (Do you think that besides taking medication, lifestyle changes are also necessary to prevent illness recurrence?): $17.90 \pm$ \pm 3.22 vs. $15.11 \pm 1.96, p=0.0033$; C (Do you think that systematic medication taking reduces the risk of reinfarction?): $18.27 \pm 3.03$ vs. $14.94 \pm 2.86$, $\mathrm{p}<0.0001$; D (Can you rely on help from your family or other people to comply with your doctor's recommendations?): $18.17 \pm 2.98$ vs. $15.50 \pm 3.24$, $\mathrm{p}=0.0001$; and $\mathrm{E}$ (Do you think your return home is associated with additional hazards?): $17.09 \pm$ \pm 3.00 vs. $17.98 \pm 3.27, \mathrm{p}=0.0377$. Similar differences in RHD-MIS subscale 3 (patient expectations) scores were found for the following opinions: $\mathrm{C}(17.79 \pm 7.25$ vs. $16.29 \pm 5.13, \mathrm{p}=0.0353)$, $\mathrm{D}(18.18 \pm 6.98$ vs. $13.38 \pm 5.59, \mathrm{p}=0.0003)$, and $\mathrm{E}(12.70 \pm 6.56$ vs. $18.91 \pm 6.50, \mathrm{p}<0.0001)$. No significant differences in ACDS score were found with regard to patient opinions expressed in the non-scored RHD-MIS items.

During 6-month follow-up $3(1.41 \%)$ patients died and 17 (7.98\%) were hospitalized for a subsequent acute coronary syndrome (ACS). Adherence levels assessed with ACDS were similar irrespective of occurrence or absence of ACS at follow-up $(22.30 \pm 3.81$ vs. $23.56 \pm 3.92 ; \mathrm{p}=0.130)$.

\section{Discussion}

Therapy according to medical guidelines has shown to be effective with regard to a reduction in illness symptoms and in the prevention of complications, however the rates of long-term adherence to pharmacotherapy tend to be as low as $50-60 \%$, regardless of the of illness, the regimen of treatment and the applied criteria [9, 16]. Available evidence suggests that patients early after hospitalization remain particularly vulnerable. Adverse events, including serious medication errors and hospital readmissions, occurred in nearly $20 \%$ of patients within 3 weeks after discharge [17]. Thus, effective preparation of patients for discharge from hospital is of great importance.
The association between readiness for discharge from the hospital and adherence to treatment assessed 6 months after discharge in patients treated for MI was the primary finding of this study. However, direct impact of readiness for discharge on clinical outcome during 6 months of follow-up was not able to be determined. This may partly be attributed to inadequate preparation for discharge of patient and his/her, poor coordination of discharge transition, and unsuccessful patient self-management at home [18].

Extensive preparation for discharge including teaching should be a standard of hospital care. However, several barriers to retention of learning at discharge have to be taken into account, including complexity of managing medical care at home, an overwhelming amount of information, the timing of teaching, as well as content relevance to personal concerns and needs [19, 20]. Although patients are prone to report receiving adequate information prior to discharge, the gaps in knowledge needed is identified when tested with questionnaires. For patients enrolled the present study the readiness for discharge level was judged high with RHD-MIS in about $1 / 3$ of patients while low in $1 / 4$ of the study population. Moreover, according to a subjective assessment the level of patient knowledge was almost two-fold higher when compared to an objective assessment of patient knowledge.

Multiple factors may contribute to adverse events after discharge, including an overwhelming quantity of information received by patients on their final hospitalization day as well as fragmented and inconsistent communication [17]. A growing body of literature suggests that to ensure patient understanding, satisfaction and safety, discharge planning should start at the time of admission [21]. Ineffective planning for discharge may result in confusion experienced by patients and their families, coping difficulties, and an increased readmission rate [22]. The implementation of a discharge planning procedure, including an assessment of patient readiness for discharge, is the first step in improving the effectiveness of hospital discharge [23, 24].

It has been previously demonstrated that the views of nurses and patients about what is important in cardiac rehabilitation are often different $[25,26]$. Moreover, models of illness represented by patients, which influence their understanding of cardiac problems, frequently differ from models represented by professionals [27, 28]. Therefore, the RHD-MIS was designed as a complex tool taking into account not only the perspective of the 
patient, but also of the nurse evaluating readiness for hospital discharge, as well as expectations and opinions of the patient [11]. Discordance was found between patient self-assessment and nurse assessment of patient knowledge in almost $60 \%$ of cases, including approximately $11 \%$ of extreme discordance.

Weiss et al. [18] showed that nurse assessment of discharge readiness was more strongly associated with post-discharge readmissions and emergency department visit utilization than patient self-assessment. Since patients with low knowledge level, according to the RHD-MIS subscale for objective assessment, are at increased risk of low adherence to treatment, they require additional motivation activities and educational intervention to avert adverse outcomes [13, 19, 29, 30].

\section{Limitations of the study}

The study was designed as a single center study, therefore the population may not be representative for other hospitals. The relatively low number of adverse clinical events at post-discharge follow-up did not permit showing any effect on readiness for discharge from hospital on clinical outcome.

\section{Conclusions}

The results of this study provide preliminary evidence of an association between assessment of readiness for discharge from hospital and adherence to treatment at long-term follow-up in patients after MI. Further testing of readiness for discharge assessment, coupled with preventive interventions targeted at improvement of adherence to treatment is needed to support rationale for implementation of such a strategy into the discharge procedure.

\section{Acknowledgments}

The authors wish to thank all the patients participating in this study.

\section{Conflict of interest: None declared}

\section{References}

1. Desai N, Choudhry N. Impediments to adherence to post myocardial infarction medications. Curr Cardiol Rep. 2012; 15(1), doi: 10.1007/s11886-012-0322-6.

2. Osterberg L, Blaschke T. Adherence to medication. N Engl J Med. 2005; 353(5): 487-497, doi: 10.1056/NEJMra050100, indexed in Pubmed: 16079372.

3. Haynes RB, McDonald HP, Garg AX. Helping patients follow prescribed treatment: clinical applications. JAMA. 2002; 288(22):
2880-2883, doi: 10.1001/jama.288.22.2880, indexed in Pubmed: 12472330.

4. Kubica A. Problems of long-term antiplatelet therapy after coronary stent implantation. Adv Interv Cardiol. 2009; 5: 158-161.

5. Kubica A, Obońska K, Fabiszak T, et al. Adherence to antiplatelet treatment with P2Y12 receptor inhibitors. Is there anything we can do to improve it? A systematic review of randomized trials. Curr Med Res Opin. 2016; 32(8): 1441-1451, doi: 10.1080/03007995.2016.1182901, indexed in Pubmed: 27112628.

6. Visser A, Deccache A, Bensing J. Patient education in Europe: united differences. Patient Educ Couns. 2001; 44(1): 1-5, doi: 10.1016/s0738-3991(01)00111-2, indexed in Pubmed: 11390150.

7. Jackevicius CA, Li P, Tu JV. Prevalence, predictors, and outcomes of primary nonadherence after acute myocardial infarction. Circulation. 2008; 117(8): 1028-1036, doi: 10.1161/CIRCULATIONAHA.107.706820, indexed in Pubmed: 18299512.

8. Forster AJ, Murff HJ, Peterson JF, et al. The incidence and severity of adverse events affecting patients after discharge from the hospital. Ann Intern Med. 2003; 138(3): 161-167, doi: 10.7326/0003-4819-138-3-200302040-00007, indexed in Pubmed: 12558354 .

9. Kubica A, Kochman W, Bogdan M, et al. The influence of undergone percutaneous coronary interventions, and earlier hospitalizations with myocardial infarction on the level of knowledge and the effectiveness of health education in patients with myocardial infarction. Adv Interv Cardiol. 2009; 5: 25-30.

10. Steg PG, James SK, Atar D, et al. ESC Guidelines for the management of acute myocardial infarction in patients presenting with ST-segment elevation. Eur Heart J. 2012; 33(20): 2569-2619, doi: 10.1093/eurheartj/ehs215, indexed in Pubmed: 22922416.

11. Buszko K, Kosobucka A, Michalski P, et al. The readiness for hospital discharge of patients after acute myocardial infarction: a new self-reported questionnaire. Med Res J. 2017; 2(1): 20-28, doi: 10.5603/mrj.2017.0004.

12. Kosobucka A, Kasprzak M, Michalski P, et al. Relation of the Readiness for Hospital Discharge after Myocardial Infarction Scale to socio-demographic and clinical factors. An observational study. Med Res J. 2018; 3(1): 32-37, doi: 10.5603/mrj.2018.0006.

13. Kosobucka A, Michalski P, Pietrzykowski $€$, et al. Adherence to treatment assessed with the Adherence in Chronic Diseases Scale in patients after myocardial infarction. Patient Prefer Adherence. 2018; 12: 333-340, doi: 10.2147/PPA.S150435, indexed in Pubmed: 29551891.

14. Kubica A, Kosobucka A, Michalski $\mathrm{P}$, et al. The adherence in chronic diseases scale-a new tool to monitor implementation of a treatment plan. Folia Cardiol. 2017; 12: 19-26.

15. Buszko K, Obońska K, Michalski P, et al. The Adherence Scale in Chronic Diseases (ASCD). The power of knowledge: the key to successful patient - health care provider cooperation. Med Res J. 2016; 1(1): 37-42, doi: 10.5603/mrj.2016.0006.

16. DiMatteo MR. Variations in patients' adherence to medical recommendations: a quantitative review of 50 years of research. Med Care. 2004; 42(3): 200-209, doi: 10.1097/01. mlr.0000114908.90348.f9, indexed in Pubmed: 15076819.

17. Forster AJ, Murff HJ, Peterson JF, et al. Adverse drug events occurring following hospital discharge. J Gen Intern Med. 2005; 20(4): 317-323, doi: 10.1111/j.1525-1497.2005.30390.x, indexed in Pubmed: 15857487.

18. Weiss M, Yakusheva O, Bobay K. Nurse and patient perceptions of discharge readiness in relation to postdischarge utilization. Med Care. 2010; 48(5): 482-486, doi: 10.1097/ MLR.0b013e3181d5feae, indexed in Pubmed: 20393364. 
19. Weiss ME, Piacentine LB, Lokken L, et al. Perceived readiness for hospital discharge in adult medical-surgical patients. Clin Nurse Spec. 2007; 21(1): 31-42, doi: 10.1097/00002800200701000-00008, indexed in Pubmed: 17213738.

20. Paterson B, Kieloch B, Gmiterek J. ,They never told us anything': postdischarge instruction for families of persons with brain injuries. Rehabil Nurs. 2001; 26(2): 48-53, doi: 10.1002/ j.2048-7940.2001.tb01925.x, indexed in Pubmed: 12035699.

21. Patel H, Mourad M. Demystifying discharge: Assessing discharge readiness to predict day of discharge. J Hosp Med. 2015; 10(12): 832-833, doi: 10.1002/jhm.2445, indexed in Pubmed: 26434568.

22. Horwitz LI, Moriarty JP, Chen C, et al. Quality of discharge practices and patient understanding at an academic medical center. JAMA Intern Med. 2013; 173(18): 1715-1722, doi: 10.1001/jamainternmed.2013.9318, indexed in Pubmed: 23958851.

23. Tyler A, Boyer A, Martin S, et al. Development of a discharge readiness report within the electronic health record-A discharge planning tool. J Hosp Med. 2014; 9(8): 533-539, doi: 10.1002/ jhm.2212, indexed in Pubmed: 24825848.

24. Weiss ME, Costa LL, Yakusheva O, et al. Validation of patient and nurse short forms of the Readiness for Hospital Discharge Scale and their relationship to return to the hospital. Health Serv Res. 2014; 49(1): 304-317, doi: 10.1111/1475-6773.12092, indexed in Pubmed: 23855675.
25. Normington K, Goodwin S. A personalised approach to cardiac rehabilitation. Prof Nurse. 2000; 15(7): 432-436, indexed in Pubmed: 11129924.

26. Kubica A, Kasprzak M, Obońska K, et al. Discrepancies in assessment of adherence to antiplatelet treatment after myocardial infarction. Pharmacology. 2015; 95(1-2): 50-58, doi: 10.1159/000371392, indexed in Pubmed: 25592409.

27. Gassner LA, Dunn S, Piller N. Patients' interpretation of the symptoms of myocardial infarction: implications for cardiac rehabilitation. Intensive Crit Care Nurs. 2002; 18(6): 342-354, doi: 10.1016/s0964-3397(02)00072-1, indexed in Pubmed: 12526872.

28. Smith J, Liles C. Information needs before hospital discharge of myocardial infarction patients: a comparative, descriptive study. J Clin Nurs. 2007; 16(4): 662-671, doi: 10.1111/j.13652702.2006.01689.x, indexed in Pubmed: 17402947.

29. Kubica A, Kasprzak M, Siller-Matula J, et al. Time-related changes in determinants of antiplatelet effect of clopidogrel in patients after myocardial infarction. Eur J Pharmacol. 2014; 742: 47-54, doi: 10.1016/j.ejphar.2014.08.009, indexed in Pubmed: 25199965.

30. Scott JT, Thompson DR. Assessing the information needs of post-myocardial infarction patients: a systematic review. Patient Educ Couns. 2003; 50(2): 167-177, doi: 10.1016/s07383991(02)00126-x, indexed in Pubmed: 12781932. 